Research Article

\title{
Research and Application of Hydraulic Punching Pressure Relief Antireflection Mechanism in Deep “Three-Soft" Outburst Coal Seam
}

\author{
Beifang $G u \mathbb{D}^{1}$ and Yanling $W u \mathbb{D}^{2}$ \\ ${ }^{1}$ School of Environmental and Municipal Engineering, North China University of Water Resources and Electric Power, \\ Zhengzhou 450046, Henan, China \\ ${ }^{2}$ School of Xingfa Mineral Engineering, Wuhan Institute of Technology, Wuhan 430073, China
}

Correspondence should be addressed to Yanling Wu; 04001073@wit.edu.cn

Received 29 April 2021; Accepted 18 June 2021; Published 1 July 2021

Academic Editor: Bo Tan

Copyright $(2021$ Beifang Gu and Yanling Wu. This is an open access article distributed under the Creative Commons Attribution License, which permits unrestricted use, distribution, and reproduction in any medium, provided the original work is properly cited.

\begin{abstract}
To solve the problems of gas predrainage in deep seams with "three softs" and low-air permeability, hydraulic punching pressure relief antireflection technology is proposed on the basis of the research background of gas predrainage technology in Lugou Mine to alleviate technical problems, such as low gas drainage efficiency, in this mine. Through the analysis of the mechanism of hydraulic punching and coal breaking, combined with FLAC3D software, a hydraulic punching pressure relief antireflection model is established. Then, the fracture radii of coal rock are simulated and calculated. The results show that, under hydraulic punching with a water pressure of $10 \mathrm{MPa}$ and coal outputs of $3 \mathrm{~m}^{3}, 6 \mathrm{~m}^{3}, 9 \mathrm{~m}^{3}$, and $12 \mathrm{~m}^{3}$, the fracture radii of coal and rock are $3.4 \mathrm{~m}, 4.8 \mathrm{~m}, 5.5 \mathrm{~m}$, and $5.9 \mathrm{~m}$, respectively. Using the software to fit the relationship between coal output $V$ and hydraulic punching fracture radius $R$ under the same water pressure, $R=2.32479 V^{0.3839}$ is obtained. The field test is carried out in the bottom drainage roadway of 32141 in Lugou Mine. The application effect is as follows: the gas concentration of hydraulic punching with a coal output of $3 \mathrm{~m}^{3}$ is twice that of ordinary drilling, and the coal output of hydraulic punching with a coal output of $6 \mathrm{~m}^{3}$ is four times that of ordinary drilling. The extraction concentration is four times that of ordinary drilling, and the extraction concentration of hydraulic punching with a coal output of $9 \mathrm{~m}^{3}$ is 6.4 times that of ordinary drilling. Combining the results of the numerical simulation and taking into account the actual construction situation on site, the coal output of water jetting from the borehole is $9 \mathrm{~m}^{3}$, and the fracture radius is $5.5 \mathrm{~m}$. This outcome means that the effective half radius is $5.5 \mathrm{~m}$, and the borehole spacing is $7.7 \mathrm{~m}$. These values are the construction parameters for large-scale applications. This proposal provides effective technology and equipment for gas drainage in the deep three-soft coal seam. Consequently, it has promotion and reference significance for gas drainage in coal seam of the same geological type.
\end{abstract}

\section{Introduction}

Coal is a basic energy source in China, and it is also an important raw material. The coal industry is also an important basic industry that is related to the country's economic lifeline and energy security. In China's primary energy structure, coal is expected to be the main energy source for a long time, which will continue to increase China's coal output [1]. The high coal output has also led to the continuous increase in the intensity of coal mining and the continuous increase in mining depth. According to data, China's coal mines are extending to the depths at an average annual rate of $10 \mathrm{~m}$ to $20 \mathrm{~m}$, and the mining depth of numerous coal mines has reached more than $1000 \mathrm{~m}$ [2]. To meet the country's rapid development of energy needs, mining deep coal must be practiced. With the increase of mining depth, the geological conditions for the occurrence of "three-soft" coal seam (soft roof, soft coal, and soft floor) have become increasingly complicated. The gas pressure increases rapidly, the ground stress rises sharply, and the 
amount of gas emission increases evidently. Moreover, the risk of protrusion increases significantly. The gas power phenomenon occurs frequently as well. Meanwhile, the original high-gas mines are gradually upgraded to coal and gas prominence mines. On-site measurement and research have shown that deep mining is not simply defined by the mining depth but also by the depth of mutation of nonlinear physical and mechanical phenomena in the engineering rock mass and the depth space below it as the mining depth increases. At the same time, it has two critical features. One is that the rock mass is in the state of in situ stress with twodirectional isostatic pressure. The other is that the selfweight stress of the rock mass has exceeded the elastic limit [3-5]. In the deep stress environment, the roof of the "threesoft" outburst coal seam is unstable. The coal seam is soft, and the firmness coefficient is low. In addition, roof falling and rib spalling are easily induced. Meanwhile, the gas flow law pattern is complicated, and gas extraction is difficult. Hence, coal and gas protrusion has been a challenging point of gas management in such mines. Among the gas accidents in China, the accidents that occur in the "three-soft" coal seam account for a high proportion. The occurrence of these accidents not only easily causes heavy casualties and economic losses, but it also produces negative social effects [6-8]. Therefore, given the characteristics of the deep stress environment, an urgent need has emerged among the majority of scientific and technological workers to study the mechanism of pressure relief and reflection improvement of the "three-soft" outburst coal seam and to provide a theoretical basis for the prediction and forecast of accidents.

To increase the permeability of low-air permeability coal seam and to improve the rate of gas drainage, scientific researchers at home and abroad have conducted extensive and in-depth research on coal seam pressure relief and antireflection technology. Studies have shown that the deep "threesoft" outburst coal seam is a hotbed of coal and gas outburst accidents. The most effective way to eliminate the high-gas energy and strain energy in the coal seam is pressure relief antireflection and high-efficiency gas drainage. The commonly used effective, safe, and economical method is to arrange through-layer drilling in the coal seam floor rock roadway to carry out hydraulic measures (hydraulic punching and hydraulic slitting) to relieve pressure and increase permeability [9-12]. Researchers at home and abroad have conducted studies on coal and rock damage and destruction under the action of high-pressure water jets. The foreign scholars Singh and Hartman first proposed the stress wave breaking theory of rock failure and failure under the action of water jet [13]. On this basis, Farmer and Attewell proposed an empirical formula of jet cutting depth and longitudinal wave velocity [14]. Furthermore, Ni et al. explored the process and mechanism of high-pressure water jet perforation, took the damage variable as the criterion of rock failure, and established a macro-micro damage coupling model of rock impacted by water jet $[15,16]$. Zhou et al. used stress wave theory to explain the phenomenon of lateral cracks in rocks under the impact of water jets [17]. Crow believed that the cavitation effect caused by the pressure difference was the main cause of rock damage during the impact of the water jet [18].
Foreign scholars have substantially researched the theory and application of hydraulic punching. In 1987, the former Soviet Union adopted hydraulic measures in 167 working faces of coal mines in the northeast of China. After the measures were taken in more than $80 \%$ of coal roadway driving faces, the gas pressure was reduced, whereas the gas extraction volume increased; moreover, the number of power outbursts and overstandard phenomena were significantly reduced, the roadway driving speed was increased, and the outburst prevention effect was remarkable [19]. Jou analyzed and studied the characteristics of the jet boundary layer; the results showed that the jet boundary layer is composed of a series of waves with different radii [20]. Bo et al. made a theoretical analysis on the coal breaking pressure of hydraulic punching and studied the coal breaking pressure required for coals of different hardness when the coal was broken by a high-pressure water jet. They proposed that the punching pressure can be washed out only when the punching pressure is higher than the uniaxial compressive strength of the coal itself [21]. As one of the first countries to study hydraulic punching, pressure relief, and antireflection technology, China has obtained rich results. The low drainage efficiency of downward drilling and other auxiliary measures have failed to achieve better outburst elimination effects; thus, to solve the technical problems regarding tight mining replacement, Yang et al. carried out a hydraulic punching test study of downward penetrating drilling, which realized the efficient pumping of hydraulic punching measures and ensured the safe and fast excavation of coal roadways [22]. In addition, Wang et al. used the numerical analysis software RFPA2D-FLOW to study the change law of coal body stress and air permeability around hydraulic punching. They applied the pressure method and content method to conduct field tests on the pressure relief range of hydraulic punching. The results showed that the distribution law of coal seam permeability around the hole is consistent with the change trend of principal stress. Moreover, the maximum principal stress of coal varies at different distances from the pressure relief area. An area closer to the hole entails a greater decrease of stress and gas pressure and a larger coal seam permeability coefficient [23]. $\mathrm{Xu}$ et al. used a self-developed hydraulic punching physical simulation test device to conduct a hydraulic punching physical simulation test. The analysis results found that the coal body in the affected area is compressed and deformed due to the pressure relief of hydraulic punching during the punching process. At the same time, the drilling imaging results reflect the shape of hydraulic punching holes and the position and shape of the cracks caused by hydraulic punching pressure relief; they also provide a theoretical basis for the analysis of the hydraulic punching pressure relief mechanism and the law of gas migration after hydraulic punching [24]. He et al. established an elastoplastic model of coal around hydraulic punching considering the plastic softening and expansion characteristics of coal; then, they analyzed the effect of pressure relief and reflection improvement of hydraulic punching and the variation law of the pore diameter; furthermore, they formulated the technology of preventing borehole blockage and gas injection 
displacement [25]. On the basis of the independent research and development of the hydraulic punching physical simulation test system, Tao et al. carried out hydraulic punching tests under several speed conditions and proposed the mechanism of hydraulic punching to relieve pressure and increase permeability [26]. Wang et al. studied the gas distribution law in the coal seam after hydraulic punching; they believed that the pressure relief antireflection area of punching will experience four processes of stress rise, crack development, rapid stress release, and restoration of balance; moreover, the area around the hole was divided into the gas discharge zone, gas pressure transition zone, and original gas pressure zone in order from near to far, respectively [27]. On the basis of the mining dynamics path, Zhang et al. studied the mechanical tests of coal containing gas at different loading and unloading rates and established the mathematical model of damage evolution based on the logistics equation [28]. Mu et al. examined the impact of the different pressures of a water jet on the formation of damage on the coal body and revealed that the coal body under the impact of a high-pressure water jet forming compression wave and stretch wave composite roles is the main reason for the damage. On the basis of the theory of spherical cavity expansion, the dynamic response of coal bodies under the impact of a high-pressure water jet is divided into broken regions, crack zones, and elastic regions; the dynamic characteristics of each region are analyzed, and the calculation formula of the crushing strength of coal bodies under the impact of the high-pressure water jet is obtained.

The "three-soft" single outburst coal seam cannot have relieved pressure and enhanced reflection through the mining protective layer. Given that the roof and floor rock mass is soft and broken and the coal structure is severely damaged, hydraulic fracturing cannot be carried out. Moreover, the coal can only be extracted by hydraulic punching, relieved pressure, and improved reflection to achieve the rapid extraction standard. Currently, hydraulic punching technology has become relatively mature, with the advantages of large coal output, good pressure relief effect, and convenient operation. It has been widely used in the field and achieved great results. The No. 1 coal seam mainly mined in the Lugou Coal Mine is a typical "three-soft" unstable coal seam in western Henan. Given its soft coal seam and low permeability, it has low drainage efficiency and poor drainage effect. Hence, the ideal extraction target is difficult to achieve, and such a challenge will also appear in the process of coal mining, outburst prediction index of unusual gas emission levels, and coal and gas outburst accidents. The hidden danger of coal mine safety is objectively difficult to eliminate. In response to the above problems, this study uses hydraulic punching technology for a deep "three-soft" coal seam. Moreover, the antireflection test based on the research of the theory of water jet breaking coal and the FLAC3D simulation of the crack under different landing radii is conducted. Then, the test is combined with the field test. The study seeks to determine the optimal coal output quantity in Lugou Mine. Moreover, it aims to improve the efficiency of the gas extraction effect and drilling construction to optimize the drilling designed to provide technical guidance for formal construction.

\section{Site Engineering Overview}

The highest gas pressure measured in Lugou Mine is $0.35 \mathrm{MPa}$, and the measured gas pressure at the 32141 working face in the $2-1$ coal seam is $0.34 \mathrm{MPa}$. The highest measured gas content in the mine is $6.44 \mathrm{~m}^{3} / \mathrm{t}$, and the highest measured gas content point is located in the west section of the 32141 working face. The gas disasters in the 2-1 coal seam of Lugou Mine mainly occur in this coal seam. The 2-1 coal seam occurs in the lower part of the Shanxi Formation, with a burial depth of $30-700 \mathrm{~m}$ and a burial elevation of $+210-600 \mathrm{~m}$. The upper distance is $65.02 \mathrm{~m}$ on average from sandstone, and the lower distance is $7.24 \mathrm{~m}$ from limestone on average. The thickness varies greatly, ranging from 0 to $19.35 \mathrm{~m}$ in thickness, with an average of $6.18 \mathrm{~m}$, and is dominated by thick coal seams. The exploitability index of the $2-1$ coal seam is 0.93 , and the coefficient of the variation of coal thickness is $78 \%$. A comprehensive evaluation of its stability is a relatively stable coal seam. The coal seam has a relatively simple structure, most of which does not contain gangue. A few boreholes contain 1-5 layers of gangue, with a thickness of $0.01-0.73 \mathrm{~m}$. The lithology is mainly carbonaceous mudstone, and the second most prevalent is mudstone. The coal seam also contains argillaceous inclusion in some sections. The false roof of the 2-1 coal seam is carbonaceous mudstone, which is unstable and easy to fall, with a thickness of $0.2-4.0 \mathrm{~m}$. The direct roof is sandy mudstone and mudstone. Meanwhile, the old roof is sandstone, mainly mediumgrained sandstone. Most of the direct floor is sandy mudstone and mudstone with fine-grained sandstone. The indirect floor is limestone.

According to the actual situation of the site, the test site was selected at the bottom tunnel of the 32141 working face. The elevation of the 32141 working face is $-325-261 \mathrm{~m}$. The working face is located to the west of the No. 32 transportation downhill. In addition, $30 \mathrm{~m}$ east of the boundary of the 16 well field is the design position of the cut lane, the north is the goaf area of the 32121 working face, and the south is the Wei Zhai normal fault and protection coal pillar line. The coal seam of this working face is unstable. The coal thickness is $1-22 \mathrm{~m}$, with an average of $8 \mathrm{~m}$. It has a scaly texture, and the block coal quality is hard with a metallic luster.

The old roof of the 32141 working face is medium-grained sand with an average thickness of $20.0 \mathrm{~m}$, which is gray, dark gray, thick layered, and medium-grained. The composition is mainly quartz, including white mica flakes and pyrite nodules. The direct top is mudstone, with an average thickness of 2.0, with argillaceous bands interbedded with thin layers of finegrained sandstone and sandy mudstone that are dark gray and rich in plant fossils and have a large number of mica slices. The direct bottom is sandy mudstone with an average thickness of $15.0 \mathrm{~m}$. It is dark gray and contains plant fossils. The composition is mainly quartz, followed by feldspar, and it contains muscovite and pyrite. The old base is limestone with an average thickness of $12.5 \mathrm{~m}$. It is black gray, dense, and hard. The karst fissures are well developed. They are rich in water and contain a lot of calcite veins and pyrite crystals. 


\section{Theoretical Analysis and Numerical Simulation}

3.1. Theoretical Analysis. Hydraulic punching protects rock pillars or coal pillars as a safety barrier. It also drills holes in outburst coal seams with self-injection capability. Moreover, it uses high-pressure water in the holes to impact and destroy the coal surrounding the drilling holes to induce and control jet holes. Coal masses migrate and produce cracks in the process of stress redistribution, which is conducive to gas pressure relief mining and achieves the purpose of preventing outbursts. Hydraulic punching is based on the mechanism of high-pressure water jet. The coal breaking mechanism of the water jet is mainly reflected in the following three aspects.

\subsubsection{The Effect of Shearing and Breaking Coal.} According to the laws of mechanics, the water jet impacts the surface of the coal body, and the effect on the coal body can be decomposed into tensile stress and shear stress. According to the Mohr-Coulomb criterion, the strength of the coal body conforms to the plane shear strength criterion:

$$
|\tau|=\sigma \cdot \tan \varphi+C
$$

Here, $\tau$ is the shear stress of the coal, MPa; $\sigma$ is the normal stress, $\mathrm{MPa} ; \varphi$ is the friction angle in the coal, ${ }^{\circ}$; and $C$ is the cohesive force in the coal, $\mathrm{MPa}$.

3.1.2. The Effect of Tensile Failure of Broken Coal. The water flow affects the coal body, and tensile cracks appear. The water flow continues to have an impact, and the cracks extend, thus causing the surrounding coal body to be subjected to tensile stress. When the tensile stress exceeds the bearing limit of the coal body, the coal body will undergo tensile failure. Finally, the stress causes the coal body to break:

3.1.3. The Role of Internal Damage and Coal Crushing. Coal is a porous medium, including pores and fissure structures. The fissures expand high-pressure jets impact them. For the purpose of modeling research, the coal fractures are believed to be in a state of unidirectional tensile stress; that is,

$$
\delta=\delta_{c}=\sqrt{\frac{\pi}{4 l_{0}}} k
$$

Here, $\delta_{c}$ is the critical stress for crack propagation, $\mathrm{MPa}$; $l_{0}$ is the original equivalent radius of the crack, $\mathrm{m}$; and $k$ is the critical value of the fracture factor of coal.

The specific process of water jet breaking coal is as follows: using high-pressure water to collide with the coal body of the borehole wall, the coal body is broken, falls off the borehole wall, and is washed out of the borehole by the water flow when the water pressure exceeds the coal breaking pressure of the coal body. After a large amount of coal in the borehole is broken and punched out of the borehole, a larger diameter hole is formed, which destroys the original stress balance state of the coal body around the borehole. This damage causes the coal body around the borehole to move to the direction of the hole by a large margin. In the state of stress balance, the stress concentration zone around the borehole moves away from the borehole, and the effective stress is reduced. When the coal body around the borehole moves toward the borehole direction, a large number of new cracks are generated. The generation of new cracks and the reduction of the stress level breaks the original body. The dynamic balance of some gas adsorption and desorption converts part of the adsorbed gas into free gas to be discharged through the cracks. The generation of a large number of new cracks and the discharge of free gas greatly reduce the elastic potential and gas expansion energy of coal and surrounding rocks. It significantly improves the permeability of the coal body. Highpressure water infiltrates the coal body through the cracks. As a result, the infiltration reduces the brittleness of the coal body, increases the plasticity, and reduces the desorption rate of residual gas in the coal body. While the hydraulic punching punches out a large amount of coal and gas, it increases the cracks in the surrounding coal body, thereby improving the drainage effect. Finally, an annular fracture zone, a plastic zone, an elastic zone, and an original stress zone are formed around the borehole, as shown in Figure 1. By studying the process of coal breaking and pressure relief of hydraulic punching, the coal output affects the key to the pressure relief under the same water jet pressure. Through the corresponding research, the optimal coal output is an indispensable procedure for studying hydraulic punching to increase permeability and pressure relief.

3.2. Numerical Simulation. To obtain the optimal coal output suitable for the enhancement and decompression of the "three-soft" coal seam, combined with the geological conditions of the area where the 32141 bottom extraction roadway was located, the hydraulic punching model was established using FLAC 3D software. In addition, the radius of the fracture area under different coal outputs was carried out. Simulation calculations were performed, and the model is shown in Figure 2. According to the experience of on-site construction, the damage range of hydraulic punch to coal was generally less than $8 \mathrm{~m}$. To simulate the damage range of hydraulic punch to coal better, the model size was set at $20 \times 20 \times 20 \mathrm{~m}$. In particular, the dimensions were as follows: a strike length of $20 \mathrm{~m}$, a dip length of $20 \mathrm{~m}$, and a vertical height of $20 \mathrm{~m}$, with a total of 115,200 units, 117,118 units, and a buried depth of $260 \mathrm{~m}$. The average bulk density of the overlying rock was $22.9 \mathrm{kN} / \mathrm{m}^{3}$. To study the failure state of coal and rock under different coal outputs more accurately, the coal body unit close to the center of the borehole was meshed densely, and the area far from the borehole was thinned out. The in situ stress in the model was obtained by theoretical calculation: $\delta_{x}=\delta_{y}=-4.1 \mathrm{Mpa} ; \delta_{z}=-5.9 \mathrm{MPa}$. The calculation formula is as follows: 


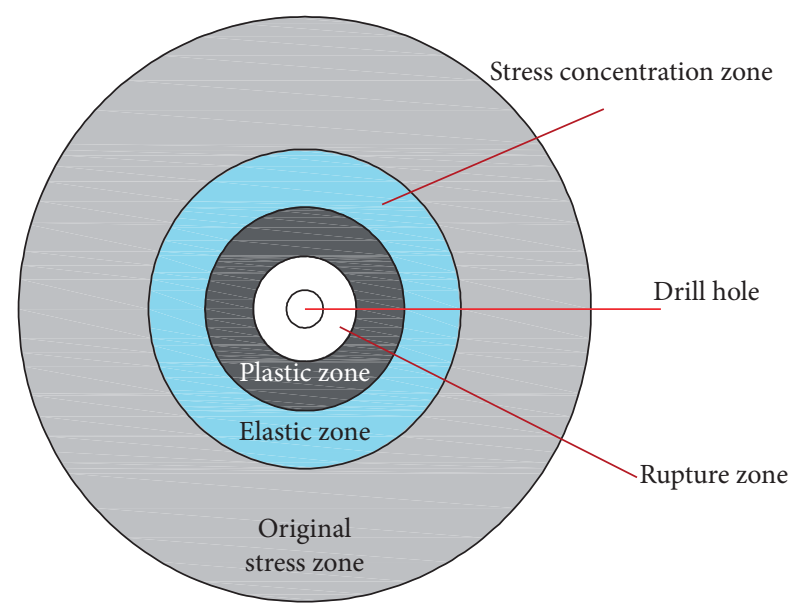

FIGURE 1: Map of stress redistribution area around the drill hole.

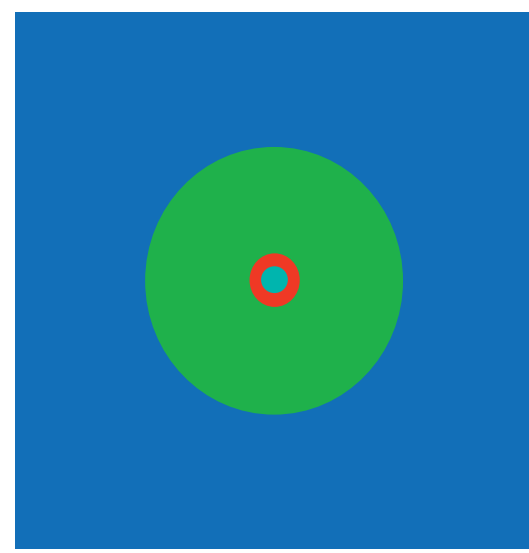

Zone

Color by: group any

$\begin{array}{ll}\text { Coal } 1 & \text { Hole } \\ \text { Coal } 2 & \text { Rock }\end{array}$

Figure 2: Physical model of hydraulic perforation.

$$
\begin{aligned}
& \delta_{z}=\gamma H, \\
& \delta_{x}=\delta_{y}=\lambda \delta_{z} .
\end{aligned}
$$

Here, $\gamma$ is the average bulk density of the overlying strata, $\mathrm{kN} / \mathrm{m}^{3} ; H$ is the buried depth, $\mathrm{m}$; and $\lambda$ is the lateral pressure system, 0.69 .

The detailed modeling process is as follows: first, the size of the model was determined, and the block mesh was built and adjusted. Then, the structural parameters of the model and material were set. Finally, the constraints and stress initialization were also set. The numerical calculation process involved model establishment, stress initialization, parameter assignment, hydraulic punching, and damage analysis. When the water pressure was $10 \mathrm{MPa}$, the coal seam fracture range with the coal outputs of $3 \mathrm{~m}^{3}, 6 \mathrm{~m}^{3}, 9 \mathrm{~m}^{3}$, and $12 \mathrm{~m}^{3}$ was simulated and calculated, respectively. Figures 3-6 demonstrate the effect of water pressure slitting coal and rock destruction when the coal outputs were $3 \mathrm{~m}^{3}$, $6 \mathrm{~m}^{3}, 9 \mathrm{~m}^{3}$, and $12 \mathrm{~m}^{3}$, respectively.

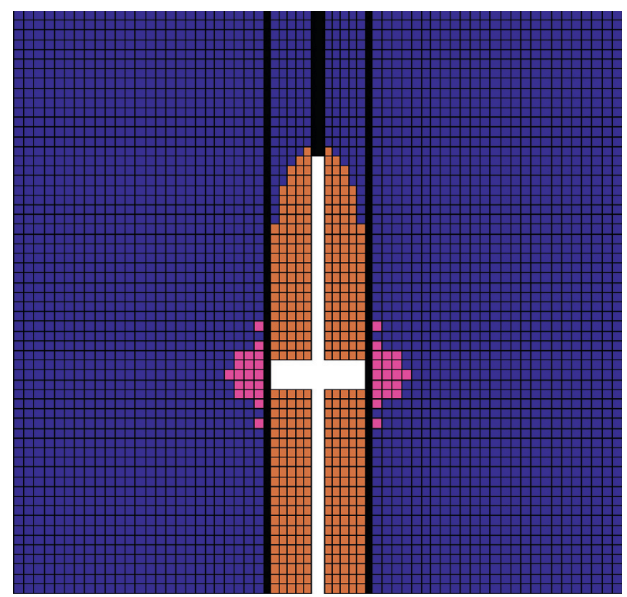

Block state

Plane: on

None

Shear- $n$, shear- $p$

Shear- $p$

FIgURE 3: The effect of water pressure slitting when the coal output is $3 \mathrm{~m}^{3}$.

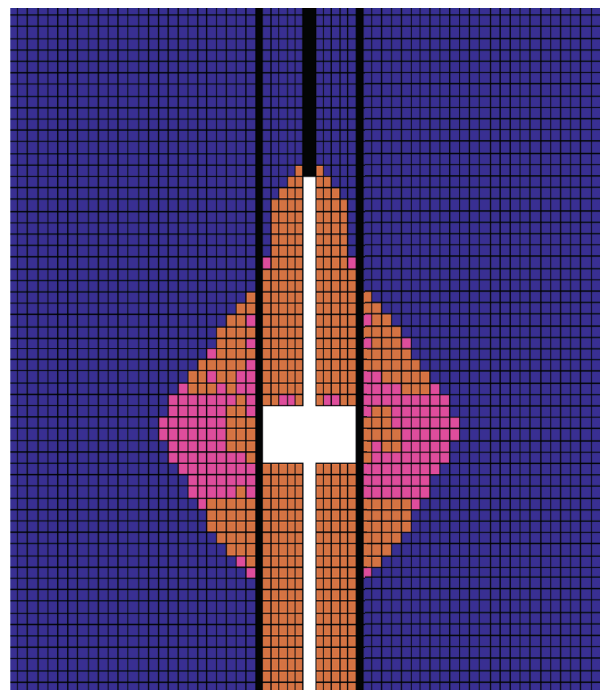

Block state

Plane: on

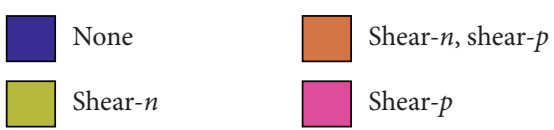

FIgURE 4: The effect of water pressure slitting when the coal output is $6 \mathrm{~m}^{3}$.

In addition, Figures 3-6 show that when the water pressure was $10 \mathrm{MPa}$ and high-pressure water jets were used for hydraulic punching, the coal broke and fell off the wall of the borehole. Moreover, it was washed out of the borehole by the water flow, thus forming a larger hole. When the coal 


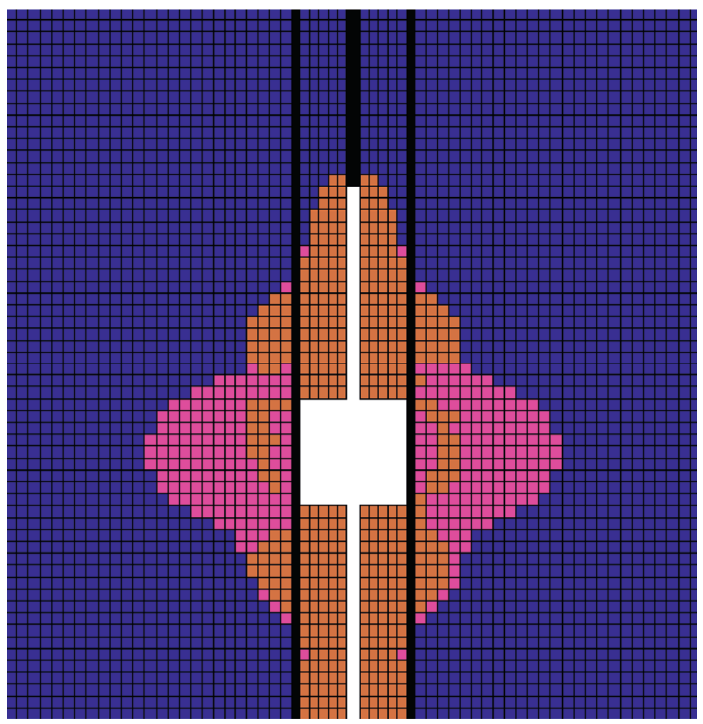

Block state

Plane: on

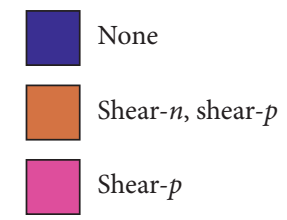

FIGURE 5: The effect of water pressure cutting when the coal output is $9 \mathrm{~m}^{3}$.

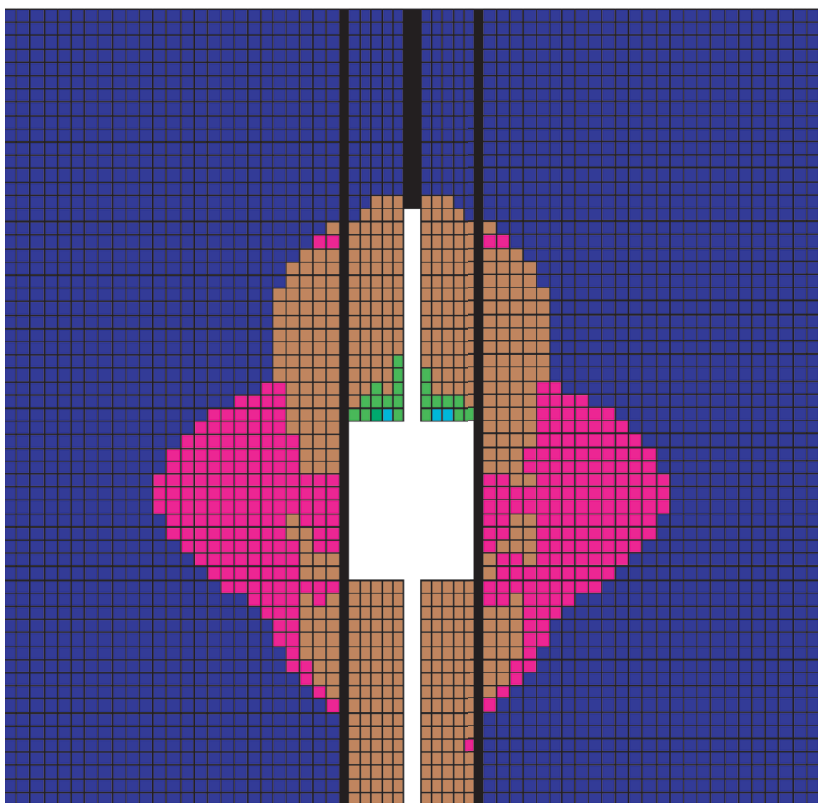

Block state

Plane: on

\begin{tabular}{ll} 
None & $\square \begin{array}{l}\text { Shear- } n \text {, tension- } n \text {, shear- } p \text {, } \\
\text { tension- } p\end{array}$ \\
$\square$ Shear- $n$, shear- $p$ & Shear- $p$ \\
\hline $\begin{array}{l}\text { Shear- } n \text {, shear- } p, \\
\text { tension- } p\end{array}$ & Tension- $n$, shear- $p$, tension- $p$
\end{tabular}

Figure 6: The effect of water pressure slitting when the coal output is $12 \mathrm{~m}^{3}$. 


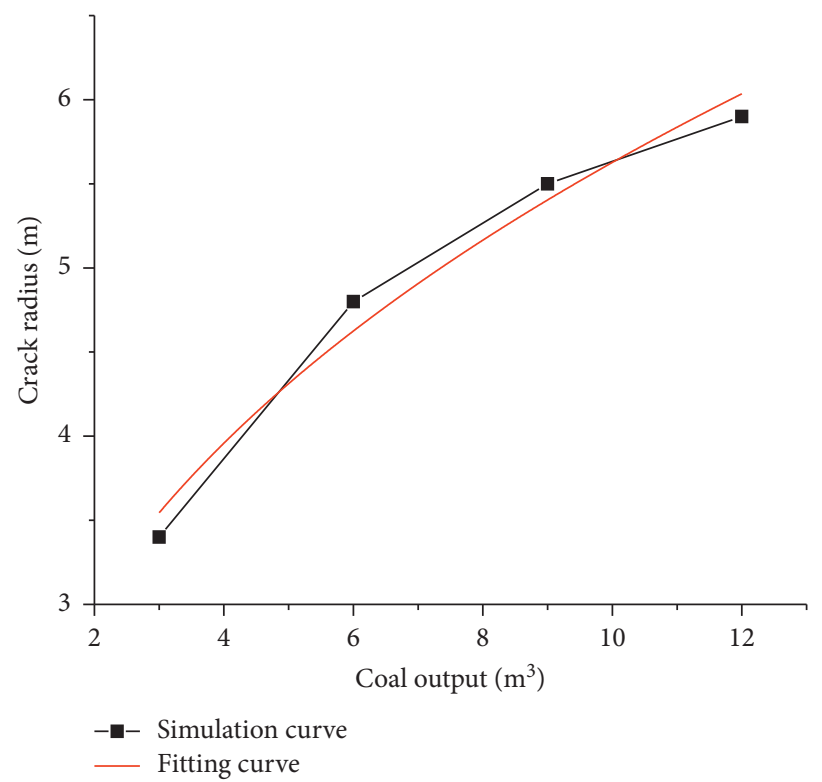

FIgURE 7: Fitting curve graph.

TABLE 1: Drilling parameters of process test.

\begin{tabular}{|c|c|c|c|c|c|c|c|}
\hline $\begin{array}{l}\text { Serial } \\
\text { number }\end{array}$ & Position & $\begin{array}{c}\text { Inclination } \\
\left({ }^{\circ}\right) \\
\end{array}$ & $\begin{array}{c}\text { Azimuth } \\
\left({ }^{\circ}\right) \\
\end{array}$ & $\begin{array}{l}\text { Drilling length } \\
(\mathrm{m})\end{array}$ & $\begin{array}{c}\text { Coal length } \\
(\mathrm{m})\end{array}$ & $\begin{array}{c}\text { Aperture } \\
(\mathrm{mm})\end{array}$ & $\begin{array}{c}\text { Coal output } \\
\left(\mathrm{m}^{3}\right)\end{array}$ \\
\hline S1 & $\begin{array}{l}14 \text { measuring point to the west } \\
23.6 \mathrm{~m} \text { left side }\end{array}$ & 26 & 180 & 41 & 19 & 113 & $\begin{array}{l}\text { Contrast } \\
\text { borehole }\end{array}$ \\
\hline S2 & $\begin{array}{l}14 \text { measuring point to the west } \\
23.6 \mathrm{~m} \text { left side }\end{array}$ & 63 & 180 & 26 & 16 & 113 & 3 \\
\hline S3 & $\begin{array}{l}14 \text { measuring point } 23.6 \mathrm{~m} \text { west } \\
\text { to the right }\end{array}$ & 74 & 0 & 28 & 17 & 113 & 6 \\
\hline S4 & $\begin{array}{l}14 \text { measuring point } 23.6 \mathrm{~m} \text { west } \\
\text { to the right }\end{array}$ & 38 & 0 & 44 & 20 & 113 & 9 \\
\hline
\end{tabular}

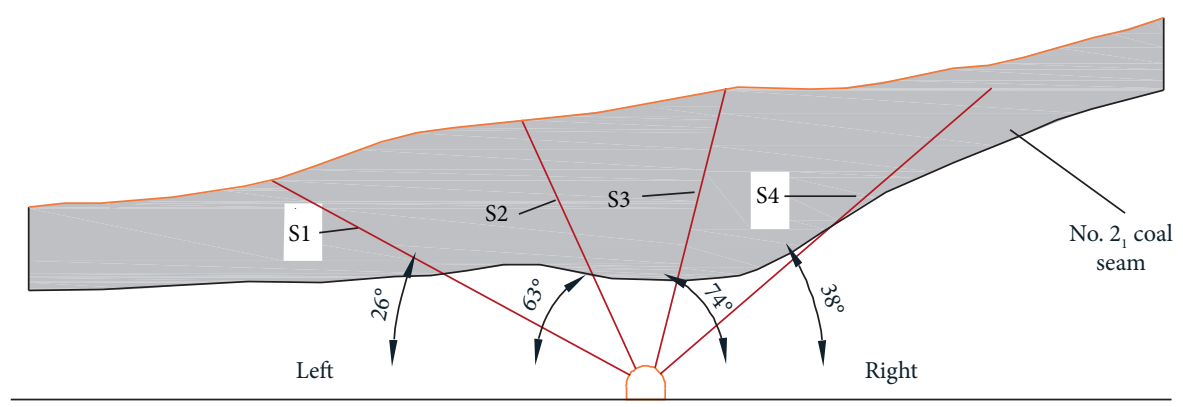

32141 bottom extraction roadway

FIGURE 8: Section of drilling arrangement of hydraulic punching test scheme.

body around the borehole moved in the direction of the borehole, a large number of new cracks were generated. The fissures around the cavities communicated with each other, and the fracturing area became larger. When the coal output was $3 \mathrm{~m}^{3}$, the coal seam fracture radius was $3.4 \mathrm{~m}$; when the coal output was $6 \mathrm{~m}^{3}$, the radius of the coal seam fracture area around the borehole was $4.8 \mathrm{~m}$; when the coal output was $9 \mathrm{~m}^{3}$, the radius of the coal seam fracture area around the borehole was $5.5 \mathrm{~m}$; when the coal output was $12 \mathrm{~m}^{3}$, the radius of the coal seam fractured area around the borehole was $5.9 \mathrm{~m}$. That is, the theoretical effective drainage radii were $3.4 \mathrm{~m}, 4.8 \mathrm{~m}, 5.5 \mathrm{~m}$, and $5.9 \mathrm{~m}$.

According to the results of the above simulation technology, the software was used to fit the relationship between the coal output $V$ and the hydraulic punching fracture radius $R$ under the same water pressure. It obtained $R=2.32479 V^{0.3839}$. The fitting result is shown in Figure 7 . Figure 7 reveals that, with the increase of coal output $V$, the 


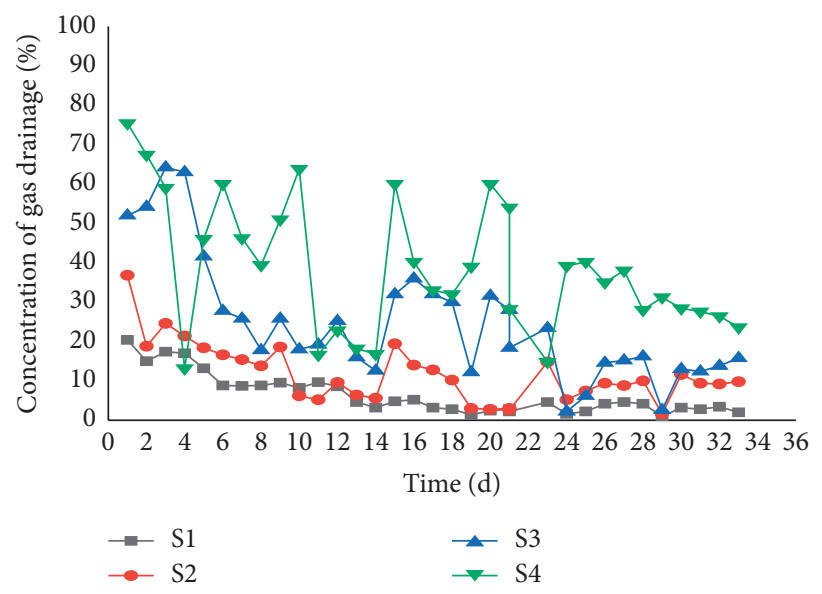

Figure 9: Concentration comparison of extracted gas.

fracture radius $R$ tended to increase rapidly and then tended to be gentle. Taking into account the actual situation, such as the state of the input cost, the optimal coal output was $9 \mathrm{~m}^{3}$, and the fracture radius was $5.5 \mathrm{~m}$; that is, the effective influence radius was $5.5 \mathrm{~m}$. To ensure that no gas extraction blank space was generated, formula (4) was calculated, which determined that the best drilling arrangement spacing $H$ was $7 \mathrm{~m}$ :

$$
H=\sqrt{2 R} \text {. }
$$

\section{Field Application Test}

4.1. Test Drilling Design. To ensure the field application effect of hydraulic punching technology, the construction site generally opted to construct stable coal seams with no faults and folds at the address. Combined with the actual situation on the spot, the test site was selected at 32141 Bottom Pumping Lane. To determine the antireflection effect of hydraulic punching with different coal output, the field application test was carried out in the bottom-drawing roadway of 32141 in the underground coal mine. Three hydraulic punching technology test holes and a control hole without hydraulic punching were initially designed. The test provided a reference basis for the optimal coal output of the formal construction design. The specific parameters of the hydraulic punching test holes are shown in Table 1 , and the layout section is shown in Figure 8. The S1 test hole was designed without hydraulic punching as a control hole, the coal output of the $S 2$ test hole was $3 \mathrm{~m}^{3}$, the coal output of the S3 test hole was $6 \mathrm{~m}^{3}$, and the coal output of the S4 test hole was $9 \mathrm{~m}^{3}$. By comparing, the extraction effect of different coal outputs could be obtained.

4.2. Analysis of Extraction Effect. In the selected construction site for perforation drilling construction, the length of the drilling reached the design position, and the drilled coal hole hydraulic perforation had a punching water pressure of $10 \mathrm{MPa}$. When the amount of coal produced reached the planned amount of coal, the next sieve tube would use the "two plugs and one note" for sealing holes, and the pumping system would be connected for extraction.

The cross-layer drilling hydraulic punching test started in late September 2020. After the gas pressure stabilized, the extraction holes were constructed and connected to the existing predrainage pipelines in the mine for gas drainage. The test boreholes began to be pumped on September 29, 2020, and 33 days of gas drainage data were collected for comparative analysis. The recording time span of each pressure measurement hole was from September 29, 2020, to the end of October 31, 2020. Figure 9 provides the details.

The statistical analysis of the 33-day test data shows that, with the continuous increase of the extraction time, the concentration of gas extraction fluctuated and decreased. Finally, it tended to be flat. Great differences were also observed in the influence of different coal output on the concentration of gas extraction. The highest concentration during the extraction process of the S1 test hole was $20.45 \%$, the lowest was $1 \%$, and the average concentration was $6.4 \%$. During the extraction process of the S2 test hole, the highest gas concentration was $36.8 \%$, the lowest was $1.6 \%$, and the average concentration was $11.58 \%$. The highest gas concentration during the extraction process of the S3 test hole was $64.44 \%$, the lowest was $2.2 \%$, and the average concentration was $24.8 \%$. The highest gas concentration during the extraction process of the S4 test hole was $75.4 \%$, the lowest was $14.8 \%$, and the average concentration was $38.58 \%$. Compared with ordinary drilling, the antireflection effect of hydraulic punching was very evident. The gas concentration of hydraulic punching with a coal output of $3 \mathrm{~m}^{3}$ was twice that of ordinary drilling, and the gas concentration of hydraulic punching with a coal output of $6 \mathrm{~m}^{3}$ was four times that of ordinary drilling. Meanwhile, the gas concentration of hydraulic punching with a coal output of $9 \mathrm{~m}^{3}$ was also 6.4 times that of ordinary drilling. A greater amount of coal output under the same water pressure entailed a higher concentration of gas extracted. The corresponding amount of gas emission also increased, thus considerably enhancing the effect of antireflection.

The study and comparison of the changes in gas concentration during the same extraction time of hydraulic 
punching holes with different coal output revealed that the amount of coal output by hydraulic punching increased, and the effect of antipermeability was greatly enhanced. Taking into account the complexity of on-site construction, the optimal drilling water jet of coal was $9 \mathrm{~m}^{3}$, as it provided technical support for the comprehensive application and construction of the hydraulic punching pressure relief antireflection technology of Lugou Mine.

\section{Conclusions}

(1) Through theoretical research on the process of hydraulic punching and coal breaking, the research finds that the amount of coal output is the key factor that affects the effect of antireflection. Then, FLAC $3 \mathrm{D}$ software is used to establish a hydraulic punching antireflection model. The collaborative pressure relief and antireflection process of different coal outputs are compared and analyzed. When the coal outputs are $3 \mathrm{~m}^{3}, 6 \mathrm{~m}^{3}, 9 \mathrm{~m}^{3}$, and $12 \mathrm{~m}^{3}$, the radius of the damage zone of high-pressure hydraulic punching in the coal body is $3.4 \mathrm{~m}, 4.8 \mathrm{~m}, 5.5 \mathrm{~m}$, and $5.9 \mathrm{~m}$; that is, the effective influence radii of the drainage are $3.4 \mathrm{~m}, 4.8 \mathrm{~m}, 5.5 \mathrm{~m}$, and $5.9 \mathrm{~m}$. Software is used to fit the relationship between coal output $V$ and hydraulic punching fracture radius $R$ under the same water pressure, thus obtaining $R=2.32479 V^{0.3839}$. With the increase of coal output $V$, the fracture radius $R$ tends to increase rapidly and then tends to be gentle.

(2) Carrying out field application test, the study concludes that after adopting hydraulic punching to increase the permeability, the gas extraction concentration of hydraulic punching with a coal output of $3 \mathrm{~m}^{3}$ is twice that of ordinary drilling. Meanwhile, in the hydraulic punching with a coal output of $6 \mathrm{~m}^{3}$, the gas extraction concentration is 4 times that of ordinary drilling, and the gas extraction concentration of hydraulic punching with a coal output of $9 \mathrm{~m}^{3}$ is 6.4 times that of ordinary drilling. The greater the amount of coal output under the same water pressure, the higher the concentration of gas extracted. The corresponding amount of gas emission also increases, thus considerably enhancing the effect of antireflection.

(3) Considering the complexity of on-site construction and investment cost, this research concludes that, under the condition of $10 \mathrm{MPa}$ water pressure, the optimal coal output suitable for Lugou Mine is $9 \mathrm{~m}^{3}$. Corresponding to the result of numerical simulation, its effective influence radius is $5.5 \mathrm{~m}$, and the spacing of the drill holes is $7.7 \mathrm{~m}$. This setting provides technical parameters for the on-site application of hydraulic punching antireflection technology in the Lugou Mine.

\section{Data Availability}

The data used to support the findings of this study are included within the article.

\section{Conflicts of Interest}

The authors declare that they have no conflicts of interest.

\section{Acknowledgments}

This work was supported by the Scientific Research Start-Up Project Funding High-Level Personnel of North China University of Water Resources and Electric Power.

\section{References}

[1] H. Zhang, "The situation and tasks faced by the development of the coal industry in the "14th five-year plan" period," Business observer, vol. 110, no. 11, pp. 58-62, 2020.

[2] C. Xu, Q. Fu, K. Wang et al., "Experimental study on the influence of loading mode on the damage-seepage time-effect characteristics of deep mining coal," Journal of China University of Mining and Technology, vol. 47, no. 1, pp. 197-205, 2018.

[3] M. C. He, "Deep conceptual system and engineering evaluation index," Chinese Journal of Rock Mechanics and Engineering, vol. 24, no. 16, pp. 57-61, 2005.

[4] Y. B. Guo, H. W. Zhou, T. L. Song et al., "Disturbance characteristics of deep coal under mining stress path," Journal of China Coal Society, vol. 43, no. 11, pp. 3072-3079, 2018.

[5] H. P. Xie, F. Gao, Y. Ju et al., "Quantitative definition and analysis of deep mining," Journal of China Coal Society, vol. 40, no. 1, pp. 1-10, 2015.

[6] Y. Zhang, F. X. Shen, X. M. Sun et al., "The stress and deformation evolution law of the surrounding rock in the secondary reuse of the roof-cutting roadway in the three-soft coal seam," Journal of China University of Mining and Technology, vol. 49, no. 2, pp. 46-53, 2020.

[7] Z. Y. Sa, L. Li, S. Q. Lu et al., "Similarity test study on the evolution of permeability of floor surrounding rock in "threesoft" coal seam with upper protective layer mining," Coal Mine Safety, vol. 48, no. 7, pp. 25-28, 2017.

[8] Z. Y. Sa, L. Wang, L. Li et al., "Pressure relief deformation and stress distribution of the underlying coal seam in mining of the upper protective layer," Coal Mine Safety, vol. 51, no. 7, pp. 61-65, 2020.

[9] Y. Han, B. W. Dong, F. Y. Zhang et al., "Research progress of hydraulic punching pressure relief and anti-reflection technology in my country," China Mining, vol. 30, no. 2, pp. 95-100, 2021.

[10] Y. Y. Lu, R. Li, X. F. Xian et al., "Discussion on high-efficiency development of deep coal bed methane by surface directional well and hydraulic slotting pressure relief method," Journal of Coal, vol. 58, no. 2, pp. 1-10, 2021.

[11] Z. Y. Cao, E. Y. Wang, X. Q. He et al., "Research on hydraulic punching pressure relief gas drainage and effect evaluation of coal seam groups with close outburst," Journal of Mining and Safety Engineering, vol. 37, no. 11, pp. 1-10, 2020.

[12] X. B. Su, J. X. Jin, H. Y. Guo et al., "Production-increasing mechanism and key technology of coal mine gas drainage," Coal Science and Technology, vol. 48, no. 12, pp. 1-30, 2020. 
[13] M. M. Singh and H. L. Hartman, "Hypothesis for the mechanism of rock failure under impact," in Proceedings of the 4th US Symposium on Rock Mechanics (USRMS), University Park, PA, USA, March 1961.

[14] I. W. Farmer and P. B. Attewell, "Rock penetration by high velocity water jet a review of the general problem and an experimental study," International Journal of Rock Mechanics and Mining Science \& Geomechanics Abstracts, vol. 2, no. 2, pp. 135-153, 1965.

[15] H. J. Ni, D. H. Wang, and Y. H. Bai, "Finite element analysis of rock breaking by high pressure water jet," Journal of the University of Petroleum, vol. 23, no. 3, pp. 37-40, 2002.

[16] H. Ni, R. Wang, and Y. Du, "Numerical simulation and experimental study on rock breaking under pulse water jet," Electronic Journal of Geotechnical Engineering, vol. 16, pp. 15-17, 2011.

[17] Q. Zhou, L. Na, C. Xi, T. Xu, S. Hui, and D. Zhang, “Analysis of water drop erosion on turbine blades based on a nonlinear liquid-solid impact mode," International Journal of Impact Engineering, vol. 36, no. 9, pp. 1156-1171, 2009.

[18] S. C. Crow, "A theory of hydraulic rock cutting," International Journal of Rock Mechanics and Mining Science \& Geomechanics Abstracts, vol. 10, no. 6, pp. 567-584, 1973.

[19] China Institute of Science and Technology Information, Compilation of Foreign Coal and Gas Outbursts, Science and Technology Literature Publishing House Chongqing Branch, Chongqing, China, 1978.

[20] M. Jou, "Analysis of the stability of water-jet cutting with linear theory," Journal of Materials Processing, vol. 104, no. 1, pp. 17-20, 2000.

[21] L. Bo, L. Mingju, L. Yanwei, W. Nianhong, and G. Xianlin, "Research on pressure relief scope of hydraulic flushing bore hole," Procedia Engineering, vol. 26, pp. 382-387, 2011.

[22] T. L. Yang, Z. F. Wang, and H. Zhao, "Experimental research on optimization of downward drilling hydraulic punching technology,” Coal Mine Safety, vol. 50, no. 3, pp. 13-16, 2019.

[23] K. Wang, B. Li, P. J. Wei, and P. Li, "Change law of coal seam permeability around hydraulic punching holes," Journal of Mining and Safety Engineering, vol. 30, no. 5, pp. 778-784, 2013.

[24] J. Xu, X. F. Wu, D. Feng, and X. P. Tang, "Research on physical simulation test of hydraulic punching," Coal Mine Safety, vol. 49, no. 1, pp. 21-24, 2018.

[25] F. C. He, L. J. Sun, and F. J. Zhao, "Spatio-temporal evolution law of coal permeability around hydraulic punching hole under the coupling effect of creep and seepage," China Safety Production Science and Technology, vol. 12, no. 8, pp. 16-22, 2016.

[26] Y. Q. Tao, D. Feng, and G. Ma, "Study on the physical simulation test of hydraulic punching and the effect of pressure relief and permeability enhancement," Coal Science and Technology, vol. 45, no. 6, pp. 55-60, 2017.

[27] X. X. Wang, B. M. Bi, and C. M. Mu, "Study on the formation mechanism of gas zoned discharge in hydraulic punched coal seams," Journal of China Coal Society, vol. 37, no. 3, pp. 467-471, 2012.

[28] M. Zhang, M. Lin, H. Zhu, D. Zhou, and L. Wang, "An experimental study of the damage characteristics of gascontaining coal under the conditions of different loading and unloading rates," Journal of Loss Prevention in the Process Industries, vol. 55, pp. 338-346, 2018. 